Bolm Inst. oceanogr., S Paulo, 28(1):165-183

\title{
OCORRÊNCIAS DE LARVAS E JOVENS DE PEIXES NA ILHA ANCHIETA (SP), COM ALGUMAS ANOTAÇÕES SOBRE A MORFOLOGIA DA CASTANHA, UMBRINA COROIDES CUVIER, 1830
}

YASUNOBU MATSUURA \& KESHIYU NAKATANI

Instituto Oceanogräfico da Universidade de São Paulo

\section{SYNOPSIS}

Occurrences of fish larvae and juveniles taken by beach seine at the Ilha Anchieta (Lat. $23^{\circ} 32^{\prime} \mathrm{S}$; Long. $45^{\circ} 05^{\prime} \mathrm{W}$ ) during the period from August 1973 to July 1974, were studied. The predominant species was Eucinostomus sp. (Gerreidae) which occurred more abundantly during summer season. Other species which occurred during hot summer season were: Albula vulpes (Linnaeus, 1758) (Albulidae), Sardinella brasiliensis (Steindachner, 1879), Harengula jaguana Poey, 1865 (Clupeidae), Trachinotus carolinus (Linnaeus, 1766), Trachinotus falcatus (Linnaeus, 1758) (Carangidae), and Menticirshus americanus (Linnaeus, 1758) (Sciaenidae). Menticirrhus littoralis (Holbrook, 1856), occurred all the year-round. Anchoa lyolepis (Evermann \& Marsh, 1902) (Engraulidae) occurred more abundantly during winter and Coleotropis sp. (Atherinidae) during autumn. Morphological description of larvae and juveniles of Umbrina coroides Cuvier, 1830 was given.

\section{NTRODUÇÃO}

0 presente estudo é uma contribuição para o conhecimento da fauna ictiológica das larvas e jovens de peixes da região de Ubatuba (SP), e faz parte do Projeto Ictioplâncton realizado em convênio entre a Superintendência do Desenvolvimento do Litoral Paulista e ofundo de Pesquisas do Instituto Oceanogräfico da Universidade de São Paulo.

As investigações foram realizadas na Ilha Anchieta em Ubatuba (Lat. $23^{\circ} 32^{\prime}$ 'S-Long. $\left.45^{\circ} 05^{\prime} \mathrm{W}\right)$, a partir de agosto de 1973 atē julho de 1974. A escolha deste local, para estudo da ictiofauna da região, deve-se ao fato de PUBL. NO 438 DO INST. OCEAN. DA USP. 
estar a ilha localizada longe das grandes cidades e, portanto, livre de qualquer tipo de poluição (Fig. 1).

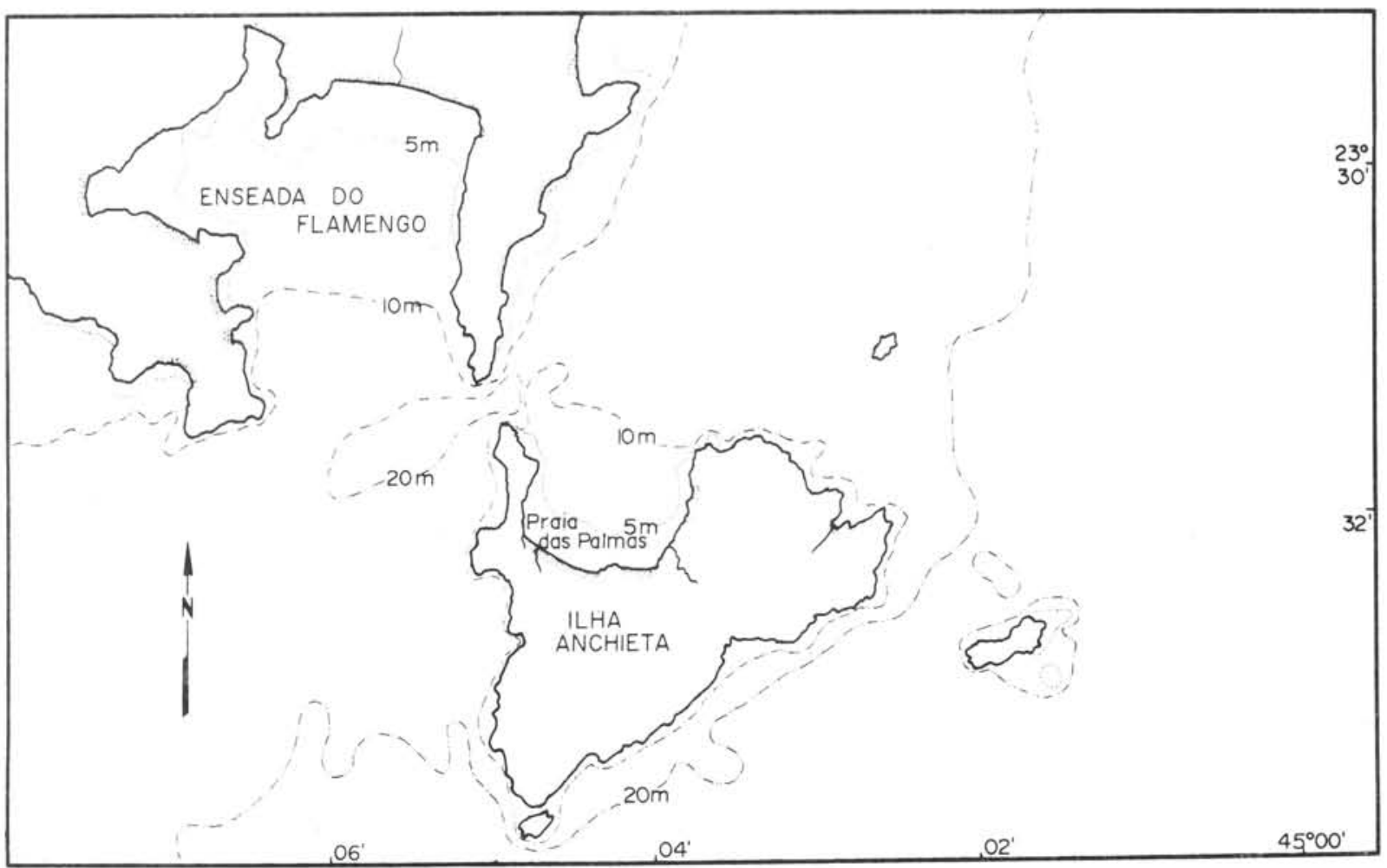

Fig. 1 - Mapa da ärea estudada, mostrando o local de coleta na I lha Anchieta (SP).

0 clima da região é tipicamente temperado. No verão, a temperatura média da ägua apresenta-se em torno de $26,0^{\circ} \mathrm{C}$ e, no inverno, ao redor de $20,0^{\circ} \mathrm{C}$, com densidade média no verão chegando a $24,0_{\sigma(15)}$ e no inverno aproximadamente $27,0_{\sigma(15)}$, conforme os dados observados no local de coleta (Fig. 2).

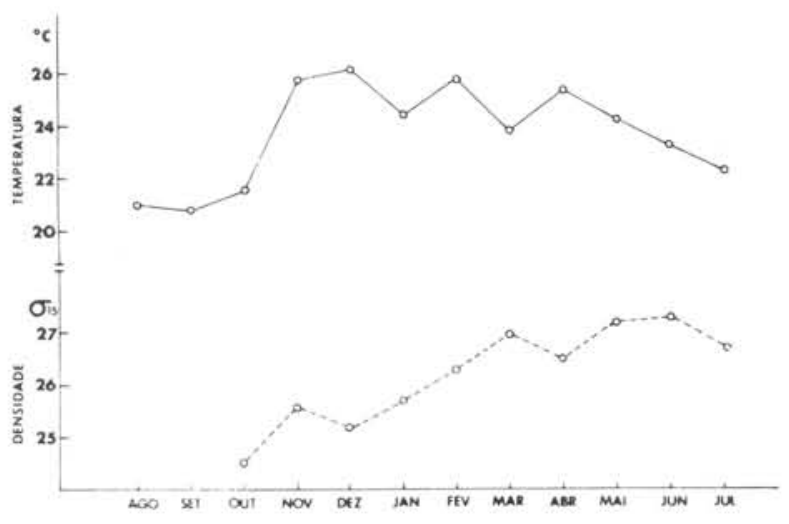

Fig. 2 - Variação da temperatura e densidade da água, no local de coleta, duranteo período de ago/73 a jul/74. 
Teixeira (1973), estudando esta região, classifica-a como sendo de baías tropicais e afirma que a produção primāria é controlada fundamentalmente pela quantidade de nutrientes disponíveis, e que hä dois sistemas de fertilização:

- águas frias, de origem oceânica;

- águas terrígenas, provenientes da drenagem devido à precipitação pluviométrica.

A partir dessas informações, podemos supor que a Enseada das Palmas forma excelente criadouro natural para o desenvolvimento de larvas e jovens de peixes e de outros tipos de animais marinhos como crustáceos, moluscos etc. Sabendo que, após os estágios planctônicos, as larvas de certos peixes marinhos aproximam-se das costas litorâneas onde poderão encontrar alimento com maior facilidade e da importância dos estudos de desenvolvimento morfológico dos peixes jovens para a identificação dos ovos e larvas que ocorrem no plâncton, planejamos as coletas de alevinos durante as diferentes épocas do ano.

o objetivo deste trabalho é analisar a ocorrência das diferentes espécies de larvas e jovens de peixes que vivem nessa região, correlacionando-a com as variações ambientais, como também mostrar vários aspectos do desenvolvimento morfológico de Umbrina coroides Cuvier, 1830.

\section{MATERIAL E MÉTODOS}

As amostragens foram realizadas mensalmente durante os anos de 1973 e 1974, na Praia das Palmas, situada na Ilha Anchieta.

As coletas foram efetuadas com rede-de-arrasto-de-praia, tipo "picaré", com as seguintes características: comprimento total de 15 por $2 \mathrm{~m}$ de altura, sendo os $10 \mathrm{~m}$ da parte central construídos com malhas de $2 \mathrm{~mm}$ entre nós e os 2,5 m de cada lado, com $100 \mathrm{~mm}$ entre nós. Devido ao tipo do aparelho, não podemos considerar as coletas quantitativamente, mas os dados obtidos poderão ser utilizados para comparações da abundância relativa durante o ano. Cada coleta constava de cinco lances de $60 \mathrm{~m}$, perfazendo um total de $300 \mathrm{~m}$ de distância, arrastada paralela à praia, em profundidades menores que $1 \mathrm{~m}$.

Os peixes coletados foram fixados em formol a $10 \%$ neutralizado e trans- 
portados para o laboratório, onde foram estudados detalhadamente. Ainda no local de coleta, foram efetuadas medidas de temperatura e densidade da água do mar.

A classificação dos peixes nos estágios de larvas, prē-juvenil e juveni1, foi baseada em Mansueti \& Hardy (1967). A identificação foi até o nível de espécie e, em alguns grupos, foi possível somente até o nível de gênero. $\mathrm{Na}$ Tabela I, relacionamos os nomes científicos e populares dos peixes coletados, para uma melhor compreensão (Brandão, 1964).

Para o presente tipo de estudo foram desprezados os indivíduos adultos capturados, como por exemplo, aqueles das famílias Atherinidae, Hemirhamphidae, Belonidae etc.

No processo de identificação dos peixes jovens pelas estruturas ósseas, foi usado o método de diafanização descrito por Taylor (1967). As larvas foram medidas com oculares graduados, usando-se escalas de transformações para milímetros e as figuras foram desenhadas com câmara clara, adaptada à lupa Wild M-5. No caso dos peixes maiores, usamos um paquímetro com leitura direta em milímetros.

TABELA I - Relação dos nomes cientificos e populares dos peixes capturados na I lha Anchieta (SP)

\begin{tabular}{|c|c|}
\hline Nome científico & Nome popular \\
\hline Albuza vulpe $\ldots \ldots \ldots \ldots \ldots \ldots \ldots \ldots \ldots \ldots$ & ubarana-mirim \\
\hline Sardinella brasiliensis $\ldots \ldots \ldots \ldots \ldots \ldots$ & sardinha-verdadeira \\
\hline Harenguta jaguana $\ldots \ldots \ldots \ldots \ldots \ldots \ldots \ldots$ & sardinha-cascuda \\
\hline opisthonema oglinum $\ldots \ldots \ldots \ldots \ldots \ldots \ldots$ & sardinha-lage \\
\hline Anchoa tyolepis $\ldots \ldots \ldots \ldots \ldots \ldots \ldots \ldots \ldots \ldots \ldots \ldots$ & $\operatorname{manjuba}$ \\
\hline Mugit spp $\ldots \ldots \ldots \ldots \ldots \ldots \ldots \ldots \ldots \ldots \ldots \ldots \ldots$ & parati, tainha \\
\hline Trachinotus falcatus $\ldots \ldots \ldots \ldots \ldots \ldots \ldots$ & pampo \\
\hline Trachinotus glaucus $\ldots \ldots \ldots \ldots \ldots \ldots$ & pampo-listado \\
\hline 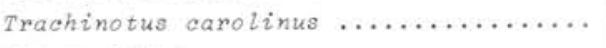 & pampo \\
\hline Caranx latus $\ldots \ldots \ldots \ldots \ldots \ldots \ldots \ldots \ldots \ldots \ldots \ldots \ldots \ldots$ & xa rẻu \\
\hline Selene vomer..$\ldots \ldots \ldots \ldots \ldots \ldots \ldots \ldots \ldots$ & peixe-galo \\
\hline oligoplites saurus $\ldots \ldots \ldots \ldots \ldots \ldots \ldots \ldots$ & guaivira \\
\hline Eucinostomus spp $\ldots \ldots \ldots \ldots \ldots \ldots \ldots \ldots \ldots$ & caradicu \\
\hline 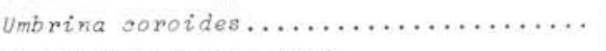 & castanha \\
\hline Menticirrhus littoralis................ & betara \\
\hline Menticirrhus americanus $\ldots \ldots \ldots \ldots \ldots$ & betara \\
\hline Paralonchurus brasiliensis ............ & maria-luiza \\
\hline Micropogon furnieri $\ldots \ldots \ldots \ldots \ldots \ldots$ & corvina-marisqueira \\
\hline Conodon nobitis $\ldots \ldots \ldots \ldots \ldots \ldots \ldots \ldots \ldots$ & roncador \\
\hline Pomatomus saltatrix $\ldots \ldots \ldots \ldots \ldots \ldots \ldots$ & anchova \\
\hline Syngnathus spp $\ldots \ldots \ldots \ldots \ldots \ldots \ldots \ldots \ldots \ldots \ldots$ & peixe-cachimbo \\
\hline Coleotropis spp $\ldots \ldots \ldots \ldots \ldots \ldots \ldots \ldots \ldots \ldots \ldots \ldots$ & peixe-rei \\
\hline Xenomelaninis brasiliensis ............ & peixe-rei \\
\hline
\end{tabular}




\section{OCORRÊNCIAS DE LARVAS E JOVENS DE PEIXES}

A freqüência de ocorrência de larvas e jovens de peixes, no período de agosto de 1973 a julho de 1974 na Ilha Anchieta, è relativamente grande. Fazendo-se uma anālise da contribuição por grupo, em porcentagem, temos o seguinte:

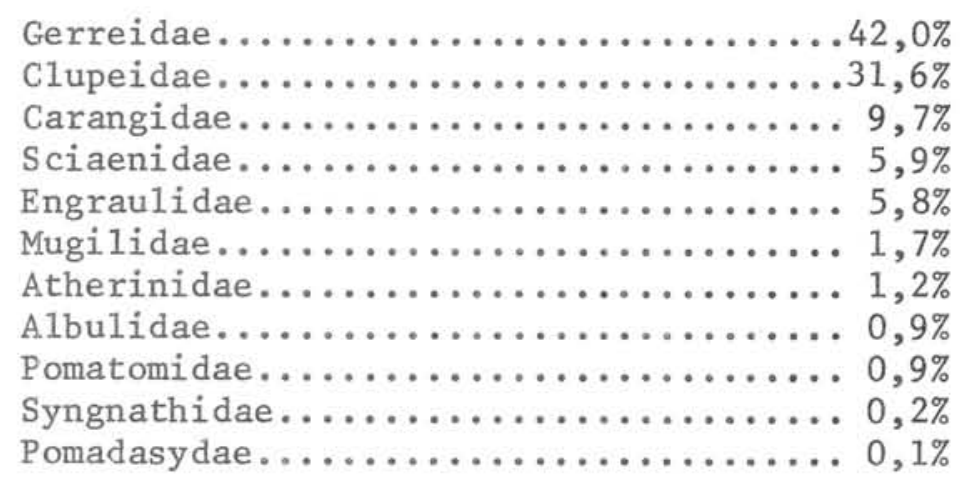

Pela relação acima, podemos observar que os grupos que ocorreram em maior freqüência foram os Gerreidae e Clupeidae, vindo a seguir outros menos importantes, complementares da ictiofauna da região.

a) GERREIDAE

0 grupo dos carapicus (Eucinostomus sp.) foi o que teve maior número de indivíduos coletados durante o ano, apresentando uma porcentagem de $42 \%$ do total de larvas e jovens de peixes coletados.

Todos os indivíduos capturados desta espécie estavam no estágio larval e apresentaram comprimento médio variando de 9,0 a $10,0 \mathrm{~mm}$ de Ls (Fig. 3), evidenciando que a ārea de desova desta espécie está próxima à costa. 0 nūmero de larvas coletadas, que ocorrem durante o ano todo, aumentou de freqüência nos meses de outubro, dezembro e janeiro (Tab. II) ocasião em que a temperatura média da água do mar estava em torno de $24,0^{\circ} \mathrm{C}$. Comparando essas informações, verificamos que esta espécie desova o ano todo e com maior intensidade no verão, ocasião em que encontra condições climäticas mais adequadas para sua reprodução. 


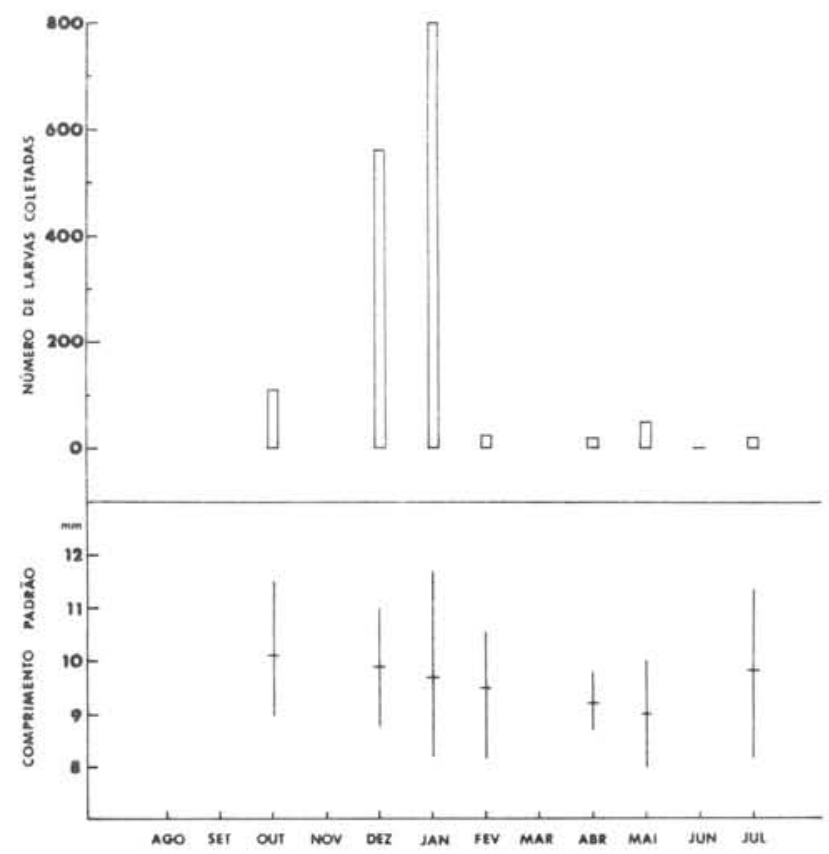

Fig. 3 - Nümero de larvas e comprimento padrão da espëcie Eucinostomus sp. (Gerreidae).

TABELA II - Ocorrência de larvas e jovens de peixes na I tha Anchieta (SP)

\begin{tabular}{|c|c|c|c|c|c|c|c|c|c|c|c|c|c|c|}
\hline Familia & Espëcie & Ago. & Set. & out. & Nov. & Dez. & Jan. & Fev. & Mar. & Abr. & Mai. & Jun. & Jul. & Total \\
\hline Albulidae & Albula vulpes & & & & 7 & 28 & 2 & & & & & & & 37 \\
\hline Clupeidae & $\begin{array}{l}\text { Sardinella brasiliensis } \\
\text { Harenguia jaguana } \\
\text { opisthonema oglinum }\end{array}$ & & & 46 & $\begin{array}{l}769 \\
249\end{array}$ & 52 & $\begin{array}{l}26 \\
30\end{array}$ & 5 & & 1 & 13 & & & $\begin{array}{r}795 \\
395 \\
1\end{array}$ \\
\hline Engraulidae & Anchoa lyolepis & 2 & 1 & 18 & & & & & & 1 & 2 & 107 & 88 & 219 \\
\hline Mugilidae & $\begin{array}{l}\text { Mugil sp. tipo I } \\
\text { Mugil sp. tipo II }\end{array}$ & & 15 & 6 & 32 & $\begin{array}{l}2 \\
1\end{array}$ & 1 & & & & & 4 & 3 & $\begin{array}{r}63 \\
1\end{array}$ \\
\hline Carangidae & $\begin{array}{l}\text { Trachinotus glauous } \\
\text { Trachinotus falcatus } \\
\text { Trachinotus carolinus } \\
\text { Caranx latus } \\
\text { Selene vomer } \\
\text { oligoplites saurus }\end{array}$ & 4 & & $\begin{array}{r}11 \\
1 \\
2\end{array}$ & $\begin{array}{l}3 \\
20\end{array}$ & $\begin{array}{r}3 \\
1 \\
115\end{array}$ & $\begin{array}{r}3 \\
17 \\
2 \\
2\end{array}$ & $\begin{array}{r}13 \\
2 \\
102\end{array}$ & $\begin{array}{r}2 \\
1 \\
12\end{array}$ & $\begin{array}{r}8 \\
25\end{array}$ & 1 & $\begin{array}{l}1 \\
1 \\
1\end{array}$ & 3 & $\begin{array}{r}49 \\
9 \\
303 \\
2 \\
2 \\
1\end{array}$ \\
\hline Gerreidae & Eucinoetomus sp. & & & 112 & & 559 & 779 & 24 & & 18 & 50 & 1 & 22 & 1.585 \\
\hline Sciaenidae & $\begin{array}{l}\text { Umbrina coroides } \\
\text { Mentioirrhus littoralis } \\
\text { Menticirrhus americanus } \\
\text { Paralonchurus brasiliensis } \\
\text { Mioropogon furnieri } \\
\text { Sciaenidae - tipo } 1 \\
\text { Sciaenidae - tipo } 11\end{array}$ & $\begin{array}{r}35 \\
3\end{array}$ & $\begin{array}{r}27 \\
1\end{array}$ & 22 & 5 & $\begin{array}{l}26 \\
1\end{array}$ & $\begin{array}{l}2 \\
1\end{array}$ & 2 & 2 & $\begin{array}{r}15 \\
5 \\
1\end{array}$ & $\begin{array}{r}13 \\
6\end{array}$ & $\begin{array}{l}7 \\
1\end{array}$ & $\begin{array}{r}37 \\
2\end{array}$ & $\begin{array}{r}191 \\
20 \\
3 \\
2 \\
1 \\
6 \\
1\end{array}$ \\
\hline Pomadasyidae & Conodon nobilis & & & & & 2 & & & & & & & & 2 \\
\hline Pomatomidae & Pomatomus saltatrix & & & & 13 & 20 & & & & & & & & 33 \\
\hline Syngnathidae & Syngnathus sp. & & & 3 & & & 1 & & & & & 2 & & 6 \\
\hline Atherinidae & $\begin{array}{l}\text { Coleotropia sp. } \\
\text { Xenomelaniris brasiliensis }\end{array}$ & 4 & & & & & & & & 2 & $\begin{array}{r}25 \\
1\end{array}$ & 12 & & $\begin{array}{r}43 \\
1\end{array}$ \\
\hline Total & & 48 & 44 & 222 & 1.100 & 812 & 886 & 149 & 17 & 76 & 120 & 138 & 159 & 3.771 \\
\hline
\end{tabular}




\section{b) CLUPEIDAE}

Besnard (1950), analisando uma ocorrência de larvas e alevinos de Sardinella brasiliensis (Steindachner, 1879) $(=S$. aurita Cuv. \& Val.) nas praias de São Sebastião, no mês de abril de 1949, após as medições de comprimento, conseguiu separar cinco modas, provando que se encontrava em presença de uma série de posturas consecutivas. No período de novembro a janeiro, capturamos sardinhas jovens que também se apresentavam em vários estágios de desenvolvimento, mostrando que os resultados obtidos por Besnard coincidem com os nossos dados.

Mateuura $(1971,1975,1977)$, estudando os ovos e larvas de Sardinella brasiliensis (Steindachner, 1879), determinou uma das āreas de desova, que fica compreendida entre a Ilha Grande e a Ilha de São Sebastião. Verificou ainda que desova no período de outubro a março e com maior intensidade nos meses de dezembro e janeiro.

Estudando a corrente de superfície da região, no período de fim da primavera até o início do outono, por meio de cartoẽs-de-deriva, chegou aos seguintes resultados:

- os cartões lançados ao mar, a este da longitude $44^{\circ} 45^{\prime} \mathrm{W}$, derivaram a nordeste e foram encontrados nas costas, entre a Ilha Grande e Cabo Frio;

- os cartoẽs lançados a oeste dessa mesma longitude, derivaram para a costa de São Sebastião e Santos.

Pela análise da freqüência do comprimento de larvas, concluiu que as larvas de sardinha-verdadeira desovadas na massa d'água da plataforma (shelf water), se dispersam em todas as direções na plataforma continental, assim como os cardumes de jovens que aparecem na região costeira, representam apenas uma parte dessa população de jovens da ägua da plataforma.

Partindo dessas informações, podemos supor que as sardinhas-verdadeiras coletadas na região de Ubatuba, nos meses de novembro e janeiro (Tab. III) são parte das desovas de alto-mar, provavelmente da região entre Ilha Grande e Ilha de São Sebastião.

Por outro lado, larvas de Harengula jaguana Poey, 1865, apareceram no 
TABELA III - Ocorrência de espëcies da família Clupeidae na I Tha Anchieta (SP)

\begin{tabular}{|c|c|c|c|c|c|c|}
\hline Est. & Data & Espècie & Larva & Pré-juvenil & Juvenil & Total \\
\hline$J-131$ & $11 / 10 / 73$ & Harengula jaguana & - & - & 46 & 46 \\
\hline$J-132$ & $20 / 11 / 73$ & $" 1$ & - & - & 249 & 249 \\
\hline$J-133$ & $06 / 12 / 73$ & $"$ & - & - & 52 & 52 \\
\hline$J-134$ & $17 / 01 / 74$ & $"$ & - & - & 30 & 30 \\
\hline$J-135$ & $14 / 02 / 74$ & $"$ & - & 2 & 3 & 5 \\
\hline$J-137$ & $23 / 04 / 74$ & " & - & 13 & - & 13 \\
\hline$J-132$ & $20 / 11 / 73$ & Sardinetla brasiliensis & - & - & 769 & 769 \\
\hline$J-134$ & $17 / 01 / 74$ & " " & - & 24 & 2 & 26 \\
\hline$J-137$ & $23 / 04 / 74$ & opisthonema oglinum & - & - & 1 & 1 \\
\hline
\end{tabular}

período de outubro a março, fazendo crer que a desova da sardinha-cascuda apresenta maior intervalo se comparada com a da sardinha-verdadeira. A ocorrência desta espécie na região de Ubatuba é representada pela fase juvenil, encontrada em maior abundância nos meses de outubro a fevereiro, e pelo estägio prē-juvenil, encontrado nos meses de fevereiro e março (Tab. III).

Com relação a Opistonema oglinum (Lesueur, 1818), foi coletado apenas um indivíduo na fase juvenil, no mês de abril. Segundo Cervigon (1966), a reprodução da sardinha-lage na Venezuela realiza-se, possivelmente, entre março e julho. Os jovens dessa espécie alimentam-se de larvas de crustáceos e outros organismos planctônicos, apresentando hábito pelágico-costeiro.

\section{c) CARANGIDAE}

Da família dos Carangidae, foram capturados jovens de quatro gêneros, representados por seis espécies diferentes (Tab. IF). o gênero Trachinotus foi o mais freqüente durante o ano, estando assim representado: Trachinotus falcatus (Linnaeus, 1758), T. glaucus (Bloch, 1788) e T. carolinus (Linnaeus, 1766) (Fig. 4).

T. carolinus é a mais abundante das três espécies e ocorreu principalmente na época de fim da primavera e começo do verão, quando a temperatura da água estava entre 25,4 e $26,2^{\circ} \mathrm{C}$. Já nos meses de janeiro, março e maio, com a temperatura do mar mais baixa, entre 23,8 e $24,4^{\circ} \mathrm{C}$, a ocorrência de indivíduos diminuiu, mostrando em parte que os jovens desta espécie têm pre- 
ferência por águas de temperatura mais elevada, uma vêz que no inverno e começo da primavera não registramos a presença desta espécie na ārea.

Considerando que os representantes desta espécie de peixe têm grande valor comercial no exterior e são, inclusive, usados em maricultura nos Estados Unidos e, considerando que a coleta de alevinos desta espécie pode ser facilmente efetuada na praia, julgamos a mais indicada para a prática de ma-

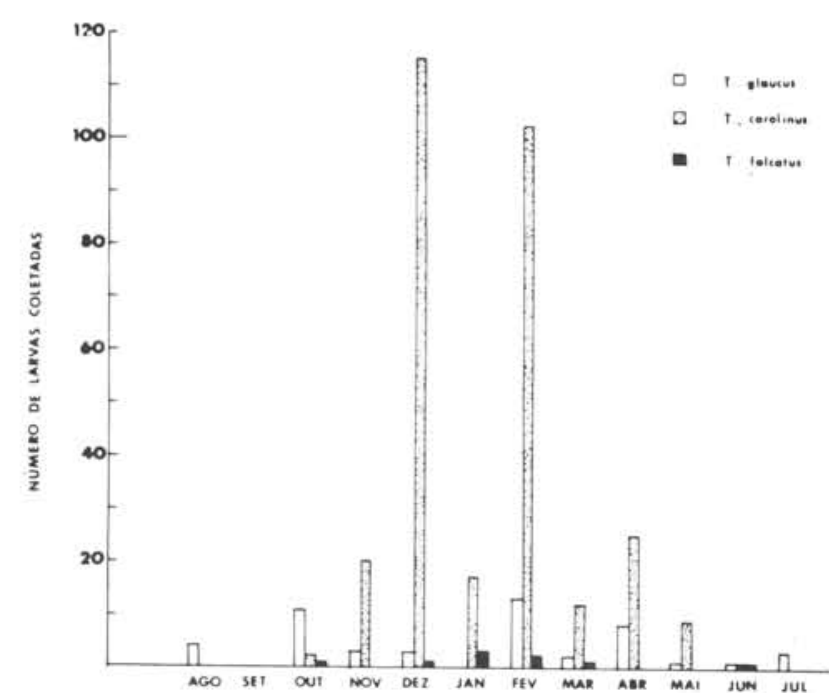

Fig. 4 - Ocorrência de larvas do gênero Trachinotus durante o período de ago/73 a jul/74 na I lha Anchieta (SP).

ricultura na região.

Com relação a T. glaucus, capturamos jovens desta espécie durante o ano todo, com exceção de janeiro e setembro, o que não significa que durante estes meses não tenha havido ocorrência da espēcie na ärea.

A captura de $T$. falcatus foi pequena em relação às outras duas espécies. Analisando o número de indivíduos coletados por mês, pode-se considerá-1a como sendo espécie do tipo de verão, como T. carolinus.

Alēm destas três espécies, foram coletados também dois jovens de Caranx: Zatus Agassiz, 1831, e dois jovens de Selene volmer (Linnaeus, 1758), no mês de janeiro, e um jovem de Oligoplites saurus (Schneider, 1801), no mês de fevereiro.

d) SCIAENIDAE

Pertencem à castanha (Umbrina coroides Cuvier, 1830) os alevinos mais 
comumente encontrados da família dos Sciaenidae. Ocorreram durante todos os meses do ano, exceto março. Analisando estas ocorrências, observamos (Fig. 5) que no mês de julho houve maior freqüência no aparecimento das fases larvärias (33 larvas, medindo $12,3 \mathrm{~mm}$ de Ls), ocorrendo também em pequena quantidade nos meses de janeiro e fevereiro, com comprimentos médios de 7,5 e 7,8 mm de Ls, respectivamente. Como as fases larvárias e juvenis apareceram em todas as estações do ano, supomos que as desovas desta espécie ocorrem durante o ano todo nas regiões costeiras.

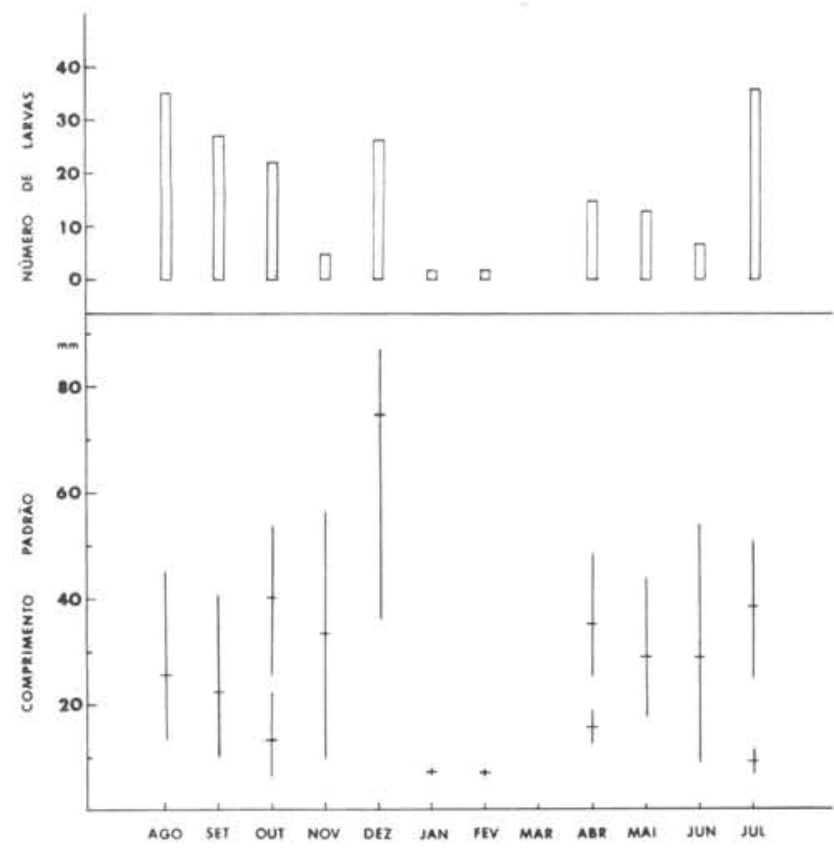

Fig. 5 - Nümero de larvas e comprimento padrão da espécie Umbrina coroides Cuvier, 1830 .

Com relação à betara (Menticirrhus littoralis (Holbrook, 1856) e $M$. americanus (Linnaeus, 1758), verifica-se pela Tabela II, que a primeira espécie ocorre de março até setembro (outono e inverno), enquanto que a segunda aparece em dezembro, janeiro e abril (verão). Comparando os diversos estágios de desenvolvimento destas duas espécies, verificamos que os alevinos de $M$. americanus capturados no mês de janeiro, apresentavam-se no estágio pré-juvenil e os capturados em dezembro e março, estavam no estágio juvenil. Enquanto que os espécimes de $M$. Zittoralis que estavam no estágio larval, apareceram somente no mês de abril, nos outros meses apresentavam-se no estágio pré-juvenil (agosto e setembro) e juvenil (março até julho). Analisando estas ocorrências com relação aos estágios de desenvolvimento, verificamos 
que $M$. Zittoralis desova no inverno e $M$. americanus no verão, ocorrendo, portanto, alternância nos períodos de desovas durante $o$ ano.

Outras espécies da família dos Sciaenidae que ocorrem nesta região são: Paralonchurus brasiliensis (Steindachner, 1875), com dois indivíduos capturados em novembro, medindo 19,0 e $28,0 \mathrm{~mm}$ de $\mathrm{Ls}$, respectivamente, e mais um exemplar de Micropogon fumieri (Desmarest, 1823), coletado em dezembro. Além dessas espécies, ocorreram ainda dois grupos que ñ̃o foram identificados, sendo, portanto, descritos como sendo dos tipos I e II.

\section{e) ENGRAULIDAE}

Da família dos Engraulidae, somente capturamos larvas e jovens da espécie Anchoa Zyolepis (Evermann \& Marsh, 1902) e a sua captura ocorreu com maior freqüência durante os meses de junho e julho, quando a temperatura média da água estava em torno de $22,0^{\circ} \mathrm{C}$ e a densidade média $27,0_{\sigma(15)}$. Podemos supor então, que a desova desta espécie ocorre no inverno, nas regiões próximas à costa, pois é o período que aparece com maior freqüência na fase larval (Tab. IV). A ocorrência sucessiva de larvas, prē-juvenil e juvenil de manjuba, na região de ubatuba, começa em abril e se prolonga até o mês de outubro, intensificando-se nos meses de junho e julho.

Analisando os diferentes estágios de desenvolvimento, verificamos que no mês de outubro, encontramos a maioria dos indivíduos na fase juvenil, enquanto que nos meses de junho e julho se apresentam no estágio de desenvo1vimento larval e pré-juvenil, comprovando realmente que as desovas desta espécie ocorrem próximo à costa, no inverno.

TABELA IV - Ocorrência de larvas e jovens de Anchoa Zyolepis (Engraulidae) na Ilha Anchieta $(\mathrm{SP})$

\begin{tabular}{|c|c|c|c|c|c|c|}
\hline Est. & Data & Espëcie & Larvas & Prë-juvenil & Juvenil & Tota 1 \\
\hline$J-127$ & $21 / 08 / 73$ & Anchoa lyolepis & - & 2 & - & 2 \\
\hline$J-128$ & $13 / 09 / 73$ & $"$ & - & 1 & - & 1 \\
\hline$J-13:$ & $11 / 10 / 73$ & " & 2 & 2 & 14 & 18 \\
\hline$J-132$ & $20 / 11 / 73$ & $"$ & - & - & - & $235 *$ \\
\hline $1-137$ & $23 / 04 / 74$ & " & - & 1 & - & 1 \\
\hline$J-173$ & $15 / 05 / 75$ & " & 1 & 1 & - & 2 \\
\hline$J-207$ & $26 / 06 / 75$ & " & 75 & 18 & 14 & 107 \\
\hline$J-208$ & $30 / 07 / 75$ & " & 42 & 46 & - & 88 \\
\hline
\end{tabular}




\section{f) MUGILIDAE}

Não nos foi possível fazer a identificação deste grupo até espécie, por falta de bibliografia especializada, portanto, identificamos até gênero: Mugil sp. tipos I eII. Os representantes desta família apresentam um certo interesse econômico para a região. Os jovens foram coletados de junho até janeiro, com exceção do mês de agosto (Tab. II).

Segundo Cervigon (1966), os adultos migram, mas näo se conhece o local $e$ as razōes que os motivam, podendo estar relacionados com a postura. Informa ainda que os exemplares menores se encontram nas orlas das praias ou em canais de lagoas, sendo portanto espécies eurihalinas, o que foi realmente observado, pois algumas coletas extras foram efetuadas na lagoa formada por um pequeno rio, próximo da praia, que se comunica com o mar durante a maré cheia.

\section{g) ATHERINIDAE}

A captura de peixe-rei adulto foi contínua durante o ano todo, mostrando assim que apresenta hábito costeiro. Um fato interessante é que alguns destes exemplares apresentavam copépodes parasitas na região das nadadeiras caudal e dorsal e na região ventral.

De jovens da família Atherinidae, foram coletados Coleotropis sp. e Xenomelaniris brasiliensis (Quoy \& Gaimard, 1824), sendo que apenas um exemplar da segunda espécie foi encontrado na fase juvenil no mēs de maio, apresentando comprimento de $27,3 \mathrm{~mm}$ de $\mathrm{Ls}$, sendo os demaịs indivíduos da espécie Coleotropis, com comprimentos que variaram de 13,0 a $25,1 \mathrm{~mm}$ de Ls. Os indivíduos que se apresentavam no estágio juvenil foram capturados nos meses de abril, maio, junho e agosto, quando a água estava com temperatura mais baixa. No entanto, não foi coletado nenhum exemplar que estivesse na fase larval ou pré-juvenil, isto porque, provavelmente, as desovas deste grupo não ocorram próximo a esta região.

\section{h) ALBULIDAE}

A captura de larvas da família Albulidae ( $T a b$. II), ocorre com maior in- 
tensidade no mês de dezembro, quando foram coletados 28 indivíduos pertencentes à espëcie Albula vulpes (Linnaeus, 1758), o que coincide com as informações fornecidas por Mansueti \& Hardy (1967), para as espécies que se encontram no Oceano Atlântico. A temperatura média da água nesta época do ano apresenta-se ao redor de $26,0^{\circ} \mathrm{C}$, o que nos leva a supor que este grupo desova durante o verão.

Cervigon (1966), descreve que os adultos desta espécie são tipicamente de águas costeiras e as larvas são planctônicas, mas no momento de sua metamorfose se aproximam da costa, ficando em baías ou enseadas. Estas informações foram comprovadas parcialmente, uma vêz que alguns dos indivíduos capturados se apresentavam no ültimo estágio de leptocéfalos ou no início de metamorfose, medindo entre 35 e $63 \mathrm{~mm}$ de Ls.

\section{i) POMATOMIDAE}

Segundo Cervigon (1966), dos representantes desta família somente se conhece uma espécie, Pomatomus saltatrix (Linnaeus, 1758), que apresenta uma distribuição cosmopolita.

Os jovens de ênchova foram coletados somente nos meses de novembro e dezembro, com temperatura da água ao redor de $26,0^{\circ} \mathrm{C}$. Não foi coletado nenhum exemplar na fase larval e pré-juvenil, o que sugere que os adultos não desovam próximo a esta região, e que os indivíduos coletados provavelmente estivessem na área à procura de alimento.

\section{j) SYNGNATHIDAE}

A ocorrência de espécies desta família foi caracterizada pela fase juvenil, tendo sido identificados somente até o nível de gênero. 0 aparecimento de Syngnatus sp. deu-se no mês de outubro, com três exemplares; em janeiro com um exemplar e em junho com dois exemplares, estando a água com temperatura de $21,6,23,2$ e $24,4^{\circ} \mathrm{C}$, respectivamente.

\section{1) POMADASYDAE}

Foram coletados em dezembro dois exemplares desta família, na Praia da 
Enseada das Palmas e identificados como sendo da espécie Conodon nobilis (Linnaeus, 1758). Nesta ocasião, a temperatura da água estava em torno de $26,2^{\circ} \mathrm{C}$ e a densidade em $22,5_{\sigma(15)}$.

Segundo Böhlke \& Chaplin (1970), os representantes desta família apresentam uma distribuição circuntropical, estendendo-se até águas temperadas.

Os indivíduos coletados em dezembro, apresentaram estágio de desenvolvimento juvenil, medindo 230 e $439 \mathrm{~mm}$ de Ls, respectivamente.

\section{DESENVOLVIMENTO DE LARVAS DE UMERINA COROIDES CUVIER, 1830}

Como, até a presente data, não encontramos nenhuma bibliografia que trate do estudo de larvas e jovens de castanha (Umbrina coroides Cuvier), e, sabendo de sua importância econômica para a pesca desta região, procuramos preencher essa lacuna apresentando alguns informes sobre o desenvolvimento morfológico da espécie.

Segundo Gilbert (1966), U. coroides distribui-se desde o nordeste da Flórida até o sudeste do Brasil, excluindo o Golfo do México, exceto seu extremo oriente e a costa do Carike na América Central e, desde o Panamá até, provavelmente, Yucatān.

Na Tabela V, apresentamos os dados merísticos de 20 indivíduos jovens de castanha da região de Ubatuba, medindo entre 15,8 a 40,8 mm de Ls, sendo uma das características principais para a identificação o 29 espinho da nadadeira anal maior que o 19 , bem como um barbilhão curto e pequeno na mandíbula e pelas listras transversais do 1ado do corpo (Cervigon, 1966).

Nas larvas de 6,86 mm de Ls (Fig. 6), as nadadeiras jä estão diferenciadas, os espinhos da dorsal estão em formação, enquanto que os raios da dorsal, anal e ventral estão completamente formados. Ccm relação à peitoral, apresentam uma membrana semi-transparente, sem evidência de raios. A membrana (fin fold), que está entre a abertura anal e o início dos primeiros espinhos da nadadeira anal, ainda não desapareceram. A cabeça da larva apresentase arrendondada, com pequenos dentes nas mandíbulas e maxilas, apresentando claramente quatro espinhos no pré-opérculo. Com relação aos cromatóforos, podemos verificar que estão distribuídos da seguinte forma: na cabeça, logo a- 
TABELA V - Dados merísticos de 20 individuos da espëcie Umbrina coroides Cuvier 1830 , coletados na I lha Anchieta (SP)

\begin{tabular}{|l|l|}
\hline No da amostra & 20 \\
\hline Comprimento padräo & $15,8-40,8 \mathrm{~mm}$ \\
\hline No de vértebras & $10+15=25$ \\
\hline Nadadeira dorsal & $x, 1,26(1), 27(9), 28(10)$ \\
\hline Nadadeira anal & 11,6 \\
\hline Nadadeira ventral & 1,5 \\
\hline Nadadeira peitoral & $17(2), 18(18)$ \\
\hline Nadadeira caudal & 9 \\
Principal-superior & 8 \\
principal-inferior & $8(19), 9(1)$ \\
procurrente-superior & $7(7), 8(13)$ \\
\hline procurrente-inferior & \\
\hline
\end{tabular}

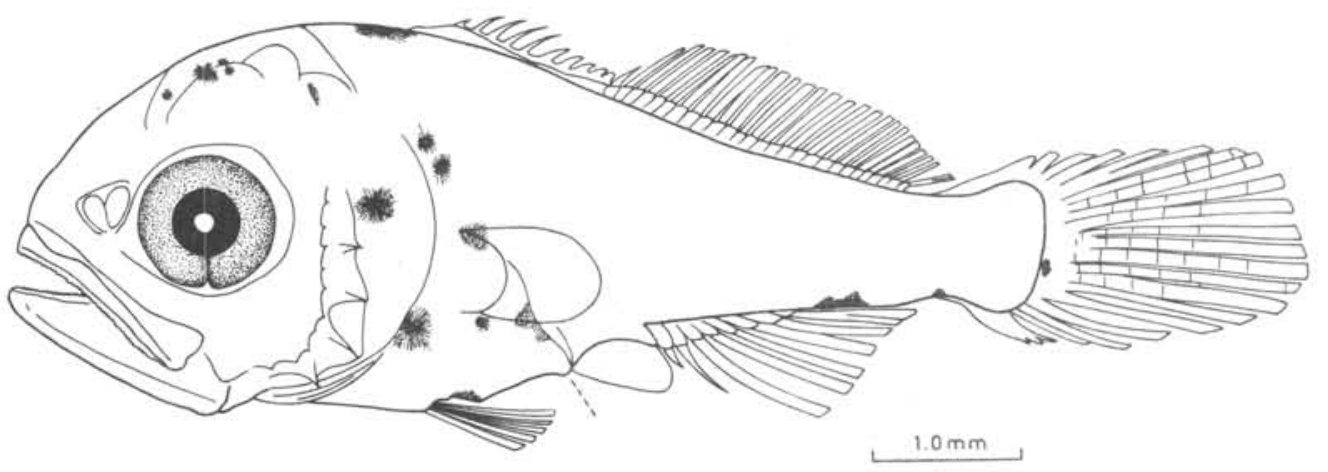

Fig. 6 - Larva de Umbrina coroides Cuvier, 1830, medindo 6,86 $\mathrm{mm}$ de Ls.

cima da região cefálica e na parte superior no opérculo; na dorsal, aparecem anteriormente aos espinhos da nadadeira; na lateral do corpo logo após a abertura do opérculo, sendo dois superiores e um inferior, estando presente ainda nas bases das nadadeiras peitorais e pedúnculo caudal próximo da nadadeira principal superior e inferior. Na região ventral, encontram-se logo após as bases das nadadeiras ventrais e anal e também no final da nadadeira caudal, anterior à procurrente inferior. Finalmente, por transparência, podemos observar cromatóforos na parte posterior da cavidade do corpo.

Com 11,1 mm de Ls (Fig. 7), verificamos que o jovem de castanha sofreu alterações no aspecto externo, principalmente com relação à distribuição dos cromatóforos, à formação dos raios das nadadeiras peitorais e aos espinhos da dorsal, que jā adquiriram características do adulto, estando inclusive os raios anais com as divisões transversais. A membrana (fin fold) diminuiu em relação ao tamanho do peixe, tendendo ao desaparecimento, o que só irá ocorrer quando atingir o comprimento de 17,3 mm de Ls. Houve um aumento 


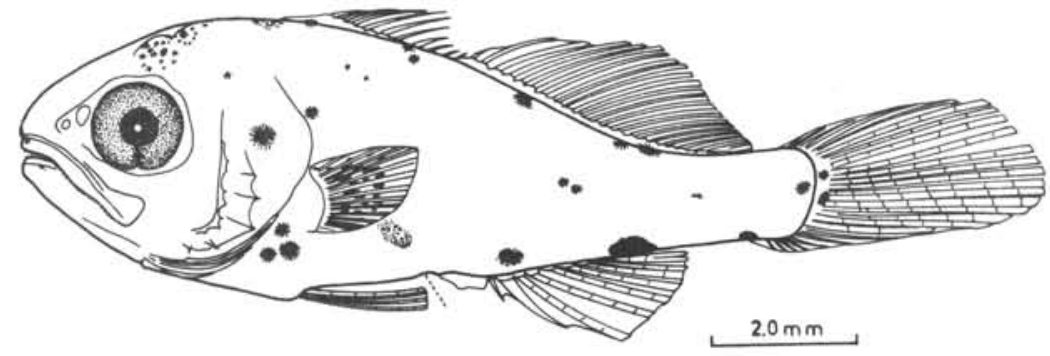

Fig. 7 - Umbrina coroides Cuvier, 1830, medindo $11,1 \mathrm{~mm}$ de Ls.

no número de cromatóforos que se localizavam na região cefálica e o seu aparecimento também em outras regiões do corpo, como: região mediana anterior e posterior da base dos raios da nadadeira dorsal, no meio do corpo em cima da linha lateral e na base da nadadeira anal, tendo desaparecido os cromatóforos da nadadeira ventral.

Atingindo 17,3 mm de Ls (Fig. 8), o jovem de castanha jā apresenta quase todos os caracteres do adulto, com exceção da distribuição dos cromatóforos, do 3ọ espinho do pré-opérculo mais saliente do que os outros, e do barbilhão da mandíbula, que só aparece com $26,0 \mathrm{~mm}$ de Ls. Inclusive a membrana

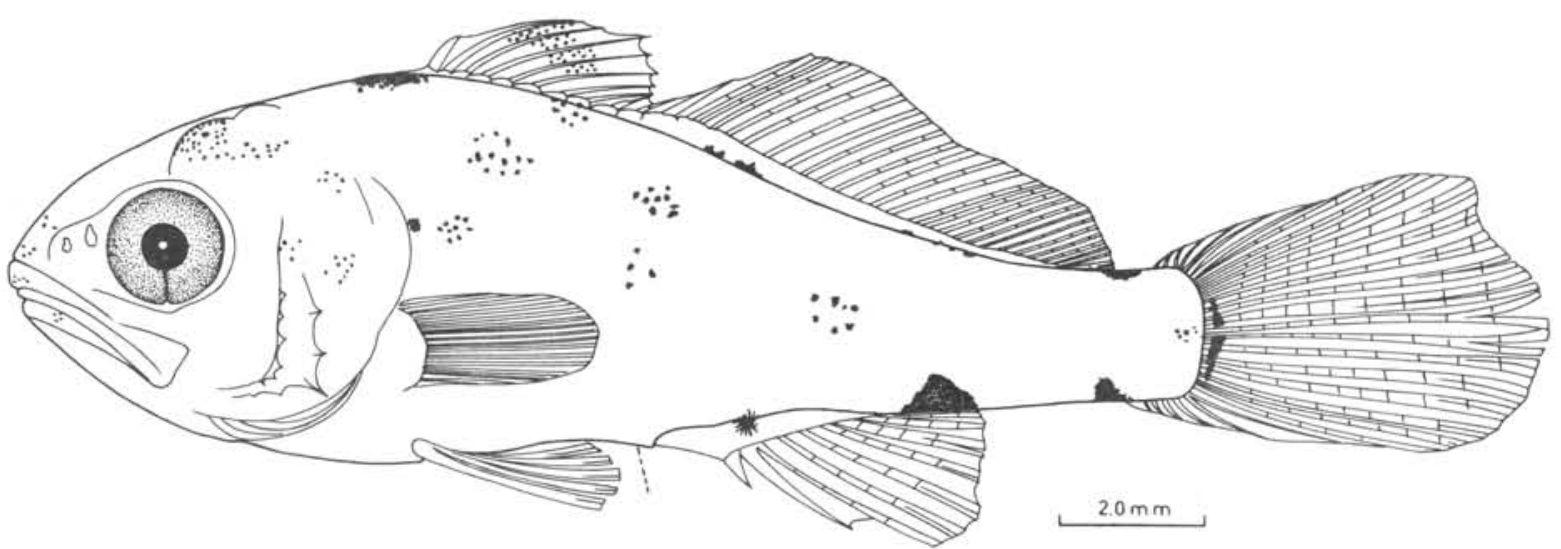

Fig. 8 - Umbrina coroides Cuvier, 1830, medindo $17,3 \mathrm{~mm}$ de Ls.

(fin fold) jä desapareceu, estando as extremidades das nadadeiras anal, caudal e ventral ramificadas. Aparecem grupos de cromatóforos na parte anterior do focinho, maxilas e mandíbulas. 0 cromatóforo grande que estava no opércu1o cedeu lugar a três grupos pequenos de pigmentações. Essas pigmentações também apareceram nas membranas do espinho dorsal e nas partes dorsal e ventral do pedúnculo caudal. Surgiram mais quatros grupos de cromatóforos, sen- 
do dois anteriores, acima da base e dois posteriores, no fim dos raios da nadadeira peitoral, dando início às estrias transversais.

As espécies que apresentam o comprimento de 23,5 mm de Ls (Fig. 9), já estão com os espinhos do pré-opérculo de forma uniforme e serrilhada e com as bordas superiores do opérculo em pequena proeminência. Pela localização dos novos grupos de cromatóforos que surgiram neste estágio, podemos evidenciar as faixas laterais do corpo, que irão permanecer na fase adulta.

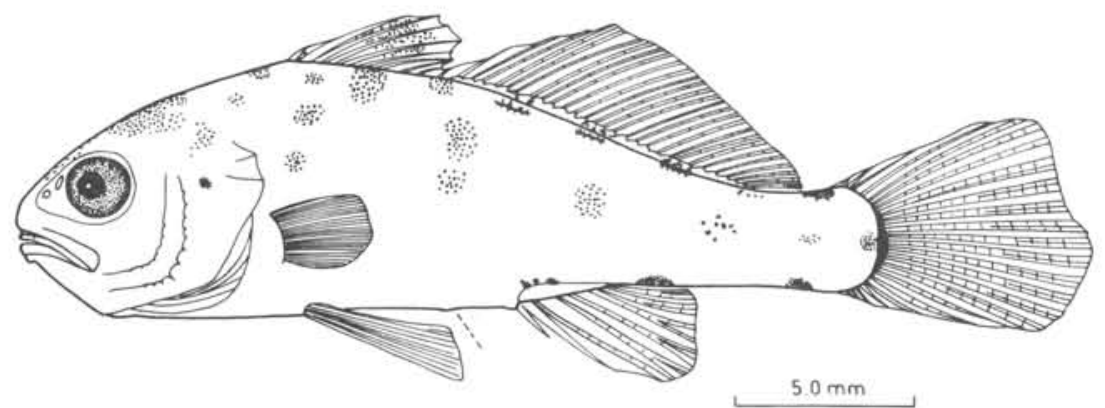

Fig. 9 - Jovem de Umbrina coroides Cuvier, 1830, medindo $23,5 \mathrm{~mm}$ de Ls.

\section{DISCUSSÃO}

Podemos dizer, de um modo geral, que a ocorrência de larvas e jovens dos peixes coletados, foi contínua durante o ano todo, com um aumento de indivíduos nos meses quentes (outubro, novembro e janeiro), enquanto que nos meses frios (de maio atë agosto) houve uma diminuição, conforme mostra a Tabela I. Isto decorre do fato de que nos meses quentes as desovas são mais intensas, principalmente nos grupos de maior freqüência de ocorrēncia, como por exemplo: Clupeidae, Gerreidae, Carangidae, etc.

Um dos objetivos deste trabalho visava à coleta de informações básicas para a implantação da maricultura e, especificamente, identificar a espécie de alevino mais abundante na região. Para tanto, foi necessārio levar em consideração três condições essenciais que também iriam influir na escolha da espécie:

- grande quantidade de alevinos no mar;

- disponibilidade de alimento;

- comercialização no mercado. 
Analisando as espécies referidas, constatamos que o pampo (Trachinotus carolinus (Linnaeus, 1766), satisfaz às condições acima citadas. A fecundação artificial de pampo não foi possível atē o presente (Bardach et al., 1972), mas a coleta de alevinos na praia, durante o período de primavera e verão, é fácil. Esta espécie tem boa cotação no mercado do Brasil e exterior (Estados Unidos), seu crescimento é rápido e atinge cerca de $50 \mathrm{~cm}$. De acordo com estudos realizados em cativeiro, na Flórida, alevinos de 0,4 a 9,4 g atingem até o máximo de $268 \mathrm{~g}$, após 133 dias de criação, enquanto que sua produção, por hectare, pode ultrapassar os $400 \mathrm{~kg}$.

Com relação a T. falcatus (Linnaeus, 1758), o crescimento também é rápido (tamanho máximo de $1,0 \mathrm{~m}$ ), mas ainda não foi estudada a possibilidade de sua criação em cativeiro. Portanto, consideramos o pampo como a espécie mais adequada para a maricultura na região.

\section{RESUMO}

Relaciona-se neste trabalho a ocorrência de 11 famílias e 26 gêneros de diferentes espécies de larvas e jovens de peixes coletados na Ilha Anchieta, Ubatuba (Lat. $23^{\circ} 32^{\prime} \mathrm{S}$ - Long. $45^{\circ} 05^{\prime} \mathrm{W}$ ), durante os anos de 1973 e 1974.

Foram analisados todos os peixes coletados, procurando-se estabelecer o período das desovas através da ocorrência dos diferentes estágios de desenvolvimento em que se encontravam, relacionando-os com as condições ambientais.

A espécie mais abundante foi Eucinostomus sp., que ocorreu principa1mente no verão. Umbrina coroides apareceu quase que durante o ano todo, Menticirrhus littoralis durante o inverno, enquanto que $M$. americanus ocorreu durante o verão. No outono, houve a ocorrência de Coleotropis sp. e a espécie mais abundante durante o inverno foi Anchoa lyolepis. Outras espécies que ocorreram em abundância durante o verão foram Albula vulpes, Sardinella brasiliensis, Harengula jaguana, Trachinotus carolinus e T. falcatus.

Apresenta-se tambēm a descrição morfológica de larvas e jovens de castanha (Umbrina coroides). 


\section{AGRADECIMENTOS}

Ao Prof. Dr. Plínio Soares Moreira, nossos sinceros agradecimentos pela revisão do manuscrito e valiosas sugestões.

\section{B IBLIOGRAF I A}

BARDACH, J. E.; RYTHER, J. H. \& MacLARNEY, W. O. 1972. Aquaculture: the farming and husbandry of freshwater and marine organisms. New York, John Wiley, 868p.

BESNARD, W. 1950. Nota preliminar sôbre uma particularidade de Sardinella aurita Cuv. \& Val., da costa brasileira. Bolm Inst. paul. Oceanogr., 1(1):69-80.

BÖHLKE, J. E. \& CHAPLIN, C. C. G. 1970. Fishes of the Bahamas and adjacent tropical waters. Wynnewood, Pa., Livingston Pub1., 771p.

BRANDÃO, J. M. 1964. Glossário de nomes dos peixes; ing1ês, sistemático, português. Bolm Estud. Pesca, 4(5):7-59.

CERVIGON, F. M. 1966. Los peces marinos de Venezuela. Caracas, Fund. La Salles de Ciencias Naturales, 951p.

GILBERT, C. R. 1966. Western Atlantic sciaenid of the genus Umbrina. Bul1. mar. Sci., 16(2):230-258.

MANSUETI, A. J. \& HARDY, J. D. 1967. Development of fishes of the Chesapeake Bay region: an atlas of egg, larval, and juvenile stage. Part I. Maryland, Natural Resources Institute, 202p.

MATSUURA, Y. 1971. A study of the life history of Brazilian sardines Sardinelia aurita. I. Distribution and abundance of sardine eggs in the region of Ilha Grande, Rio de Janeiro. Bolm Inst. oceanogr., S Paulo, $20(1): 33-60$.

1975. A study of surface currents in the spawning area of Brazilian sardine. Bolm Inst. oceanogr., S Paulo, 24:31-44.

1977. O ciclo de vida da sardinha-verdadeira (Introduçãc à oceanografia pesqueira). Publção esp. Inst. oceanogr., S Paulo, (4): $1-146$.

TAYLOR, W. R. 1967. An enzyme method of clearing and staining small vertebrates. Proc. U.S. natn. Mus., 122(3596):1-17.

TEIXEIRA, C. 1973. Preliminary studies of primary production in the Ubatuba region (Lat. $23^{\circ} 30^{\prime} \mathrm{S}$ - Long. $45^{\circ} 06^{\prime} \mathrm{W}$ ), Brazil. Bolm Inst. oceanogr., S Paulo, 22:49-58. 